\title{
AVALIACÃO DE CONCHAS DO MEXILHÃO Perna perna VISANDO AO APROVEITAMENTO NO DESIGN E ARTESANATO
}

\author{
Perna perna mussel shell evaluation \\ aiming it's use in design and crafts
}

\author{
Daniel Shimada Brotto', Lucília Tristão Ramos² \\ ${ }^{1}$ Centro Integrado de Estudos em Turismo e Hotelaria. E-mail: danshima63@gmail.com \\ 2 Universidade Estácio de Sá. E-mail: luciliaramos@uol.com.br
}

\begin{abstract}
RESUMO
Este trabalho visou avaliar conchas do mexilhão Perna perna, cultivadas e não cultivadas, para uso em design e artesanato. As amostras vieram de descartes em locais específicos em Niterói, no Rio de Janeiro. Registrou-se a superioridade das conchas cultivadas quanto à simetria, qualidade do nácar e padronização no formato e tamanho. $\mathrm{O}$ uso desse resíduo oferece uma oportunidade para o desenvolvimento comunitário, além de ser uma alternativa de mitigação válida para reduzir o impacto do descarte de conchas na natureza.
\end{abstract}

Palavras-chave: resíduos sólidos, madrepérola, sustentabilidade.

\section{ABSTRACT}

This work aimed to evaluate Perna perna mussel shells, cultivated and non-cultivated for its use in design and crafts. The samples came from discards at specific locations in Niterói-RJ. The superiority of cultured shells was recorded, regarding symmetry, quality of the nacre and standardization in the format and size. The use of this residue provides an opportunity for community development, as well as being a valid mitigatory alternative to reduce the impact of shell discards in nature.

Keywords: solid waste, mother of pearl, sustainability.

Recebido em: 30/4/2019

Aprovado em: 22/11/2019

Publicado online em: $20 / 3 / 2020$ 


\section{INTRODUÇÃO}

Segundo Manzini e Vezzoli (2011), o design está entre as principais fontes poluidoras em vários segmentos, principalmente aqueles que abarcam objetos e bens de consumo com uma breve vida útil. Segundo Karsson e Luttrop (2006), Vezzoli (2005), Ryan (2004a) e Charte e Tishner (2003), o design sustentável tem aumentado seu alcance e o seu entendimento, trazendo a promoção de novos critérios de qualidade sustentáveis, socialmente aceitos e atraentes.

O uso de materiais de origem natural para o desenvolvimento de objetos de design e de artesanato deve ser feito de forma responsável, seguindo as leis e normas correspondentes e tendo-se em mente as questões relacionadas à sustentabilidade, à qualidade do produto e ao impacto causado no meio ambiente.

No Brasil, o mexilhão Perna perna (Linnaues, 1758) ocorre, principalmente, entre o Espírito Santo e o Rio Grande de Sul (Resgalla Jr. et al., 2008), sendo a sua concha um abundante resíduo sólido natural. Esse estudo visou avaliar o seu potencial como matéria-prima no design de moda, além de fomentar a reflexão para a mudança de pensamento sobre a sustentabilidade do design de moda, onde, na definição de ecologia industrial, o termo resíduo assume outro significado: passa a ter a conotação de insumo em um novo processo de produção.

As conchas e sua parte interna de madrepérola, procedentes de cultivos ou de populações naturais, são utilizadas de longa data, com diversas aplicações, como em utensílios, artigos religiosos, amuletos, joias, adornos para móveis e roupas, revestimentos na arquitetura e objetos de arte (Thomas, 2007). O uso de conchas de mexilhão residuais de cultivos para o desenvolvimento de produtos de design e artesanato torna-se bastante atraente, por serem resíduos sólidos de difícil degradação, encontrados em larga escala, e pelas suas qualidades estéticas.

As conchas de mitilídeos são de grande potencial para o desenvolvimento de objetos de design; no entanto, no que tange à sustentabilidade da aquisição e à qualidade estética, essa matéria-prima requer alguma preocupação quanto à sua origem, uma vez que a sua extração de bancos naturais pode acarretar danos ambientais, pois suas agregações naturais ocorrem em ecossistemas com uma grande diversidade de organismos associados, além de originar conchas com formatos e nácar não padronizados. Briones e Guiñez (2005) registraram índices elevados de assimetria entre pares de valvas de mitilídeos, explicando-a pela estratificação do habitat natural e as diferentes densidades populacionais desses moluscos. Lajus et al. (2015) também observaram essa assimetria e relacionaram-na a fatores climáticos. Ferreira e Magalhães (2004) chamaram a atenção para variações na morfologia das conchas de bivalves, derivadas de diferentes habitats.

Considera-se que o aproveitamento desses materiais, quando resíduos de cultivos, pode reduzir os impactos sociais e ambientais advindos do seu acúmulo e simultaneamente criar a oportunidade para o desenvolvimento comunitário em moldes sustentáveis, além de proporcionar a oportunidade para concientização do profissional envolvido, do cidadão comum e do consumidor para o tema da sustentabilidade. Como salientam Freitas e Barroso (2006), a aquicultura moderna deve pautar-se em moldes que conciliem os interesses econômicos e a preservação ambiental. Segundo Ostrensky et al. (2007), o mexilhão Perna perna consiste no molusco marinho mais cultivado no Brasil e, certamente, pode-se inferir que o acúmulo de suas conchas onde ele é processado seja um aspecto bastante negativo do seu cultivo. 
O assoreamento destaca-se como um dos problemas causados pelo acúmulo das conchas, derivados de um descarte desordenado nas zonas costeiras. Em locais de cultivo, a sedimentação das conchas e os vários resíduos no fundo acabam por prejudicar o ecossistema e o próprio cultivo. Como relatam Chierighinia, Bridib et al. (2011), nos cultivos de bivalves, a sedimentação é um problema para o próprio cultivo, pois as cordas e lanternas que ficam em contato com o sedimento deixam os moluscos mais vulneráveis aos predadores e também mais propícios a desgastes e incrustações nas estruturas de cultivo. Por fim, o material mais rígido e cortante das conchas pode ocasionar ferimentos aos banhistas e produtores. Nos terrenos mais afastados do contato com o mar, o descarte indevido da concha gera mau cheiro, provocando o desenvolvimento de vetores de contaminação e doenças.

Segundo a norma NBR 10.004/1987 definida pela ABNT, os resíduos sólidos são classificados como: “(...) Resíduos nos estados sólido ou semi-sólido, que resultam de atividades de origem industrial, doméstica, hospitalar, comercial, agrícola, de serviços e de variação (...)" (Associação Brasileira de Normas Técnicas, 1987).

De acordo com a mesma norma, as conchas podem ser classificadas como resíduos sólidos classe II A - não perigosas, não inertes, podendo ser dispostas em aterros sanitários ou reciclados, entretanto, devem ser observadas as matérias orgânicas ou "partes moles" contidas em suas cavidades. São consideradas como dificilmente degradáveis (DD).

Na enseada de Jurujuba, no município de Niterói, no Rio de Janeiro, está implantada uma extensa atividade de mitilicultura desde 1970/80 (Ritter, 2013). Essa atividade tornou-se a alternativa encontrada pela comunidade de pescadores locais ao colapso da atividade pesqueira, sendo o processamento e o descarte das conchas efetuados no mesmo local. Próximo dali, estão localizados vários afloramentos rochosos como os da Pedra da Itapuca, que consiste em um dos vários locais explorados por extrativistas denominados marisqueiros, que, munidos de raspadeiras, coletam mexilhões dos bancos naturais e lá mesmo o processam, descartando as conchas no local. Levando-se em conta que os mexilhões $P$. perna em cultivos do tipo "long line" e em costões rochosos têm seu desenvolvimento moldado pelas variações na exposição ao batimento, à atmosfera, ao calor e à luz, além de tempo de forrageamento, pode-se supor que nos "long lines" ocorrerá uma maior homogeneidade nas conchas. Assim, este trabalho tem o objetivo de avaliar e identificar diferenças morfológicas entre conchas obtidas de cultivos em "long lines" em Jurujuba e de costões rochosos na Pedra da Itapuca, considerando o uso desse resíduo no design e artesanato.

\section{MATERIAL E MÉTODOS}

Foram obtidas amostras de conchas de P. perna descartadas após processamento nos seguintes locais: nas proximidades da Pedra da Itapuca, em Icaraí, e na Ponta da Ilha, em Jurujuba, ambos no estado de Rio de Janeiro, em setembro de 2013, respectivamente originadas da extração de bancos naturais e da mitilicultura.

Cada amostra foi acondicionada em saco plástico e armazenada sob refrigeração por um período máximo de 24 horas. Depois, foram obtidos seus pesos totais e feita a triagem das seguintes categorias: conchas maiores de $5 \mathrm{~cm}$, juvenis com partes moles, bisso, organismos incrustantes, cacos de conchas, cascalho mineral e conchas menores de $5 \mathrm{~cm}$. As conchas maiores de $5 \mathrm{~cm}$ caracterizam-se como o material aproveitável para o design e artesanato, sendo as demais categorias consideradas resíduos não aproveitáveis. 
De cada amostra (Itapuca e Jurujuba), foram retiradas aleatoriamente 40 conchas com comprimento igual ou acima de $5 \mathrm{~cm}$, para a mensuração mais acurada de seus comprimentos e alturas, feita por meio de paquímetro com precisão de 0,01 $\mathrm{mm}$.

Os dados resultantes das análises laboratoriais foram digitados em planilhas eletrônicas para avaliação das diferenças entre as proporções de resíduos e material aproveitável nas amostras procedentes dos diferentes locais, assim como a distribuição de frequências por classes de altura em cada local de coleta, da definição da reta de regressão e do coeficiente de correlação para comprimento $(\mathrm{mm}) \times$ altura $(\mathrm{mm})$ e da avaliação da razão entre altura e comprimento das conchas oriundas de cada local (Jurujuba e Itapuca). Essas avaliações foram feitas por meio de representações gráficas e testes de significância (Quiquadrado e Teste $\mathrm{t}$ ).

\section{RESULTADOS E DISCUSSÃO}

Foi registrada uma diferença significativa (Qui-quadrado $=423,3 ; \mathrm{GL}=1 ; p<0,1 \%$ ) entre as amostras procedentes da Itapuca e de Jurujuba. Essa diferença se explica pela inversão na proporção dos pesos dos materiais aproveitáveis e resíduos não aproveitáveis entre os dois locais de coleta, com a significante superioridade no peso do material aproveitável na amostra de Jurujuba (Figura 1).

Figura 1 - Peso em gramas dos resíduos aproveitáveis e não aproveitáveis oriundos da exploração do banco natural da Itapuca e da mitilicultura de Jurujuba

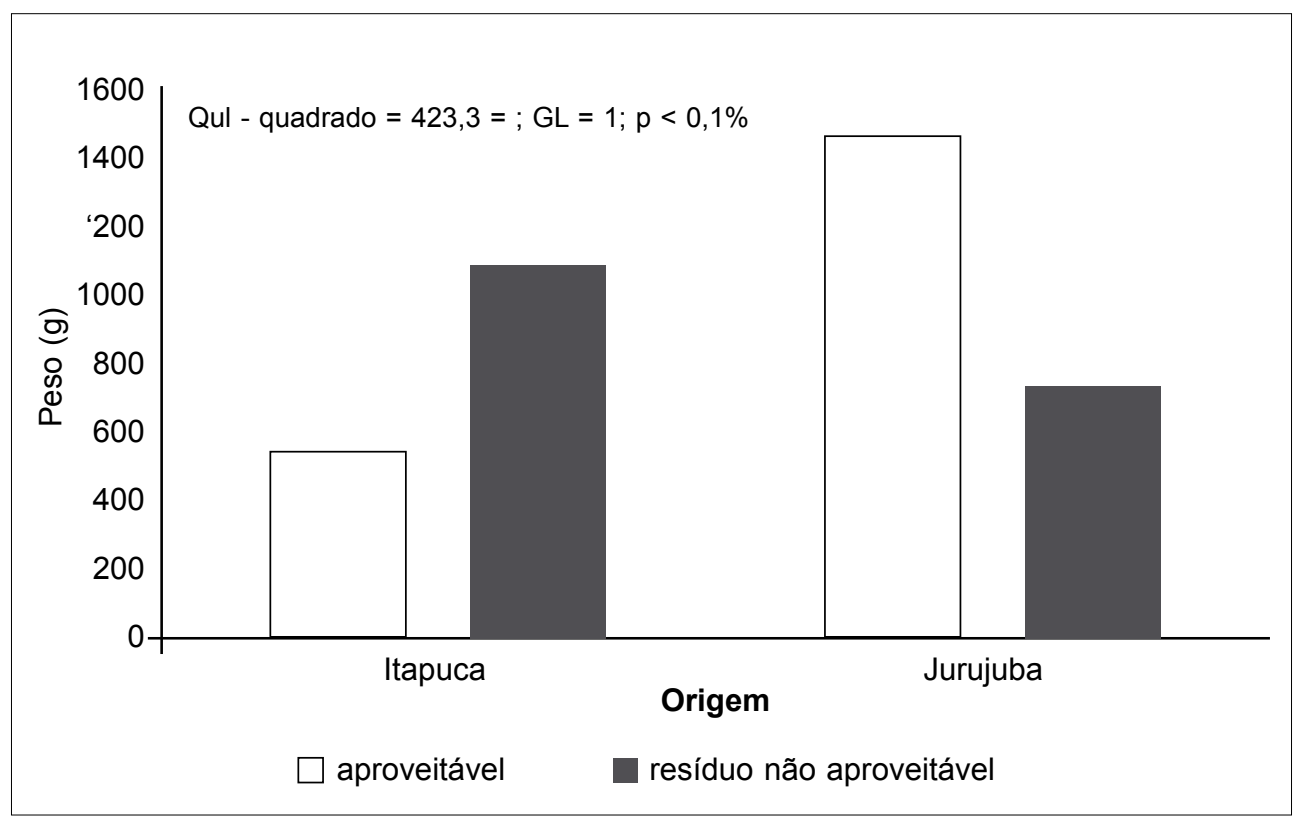

Registrou-se um maior peso percentual (Figura 2B) e diversidade na composição de resíduos não aproveitáveis na amostra oriunda da Itapuca. Também chama a atenção que os juvenis com partes moles e os cascalhos minerais só ocorreram nessa amostra (Figura 2A).

Considerando-se as maiores dimensões, a simetria e a padronização no formato das conchas como quesitos importantes para o aproveitamento no design e no artesanato, constatou-se que a amostra de Jurujuba possui maior potencial, entendendo-se que a correlação positiva e forte $(r=0,857)$ entre comprimento e altura da concha seja indicador 
dessa simetria e padronização, além do que as conchas de Jurujuba tiveram alturas de 55 a 110 mm, visivelmente superiores às da Itapuca, que variaram entre 53 e 77 mm (Figura 3).

Figura 2 - Peso absoluto (A) e percentual (B) em gramas de cada componente dos materiais oriundos da exploração do banco natural da Itapuca e da mitilicultura de Jurujuba

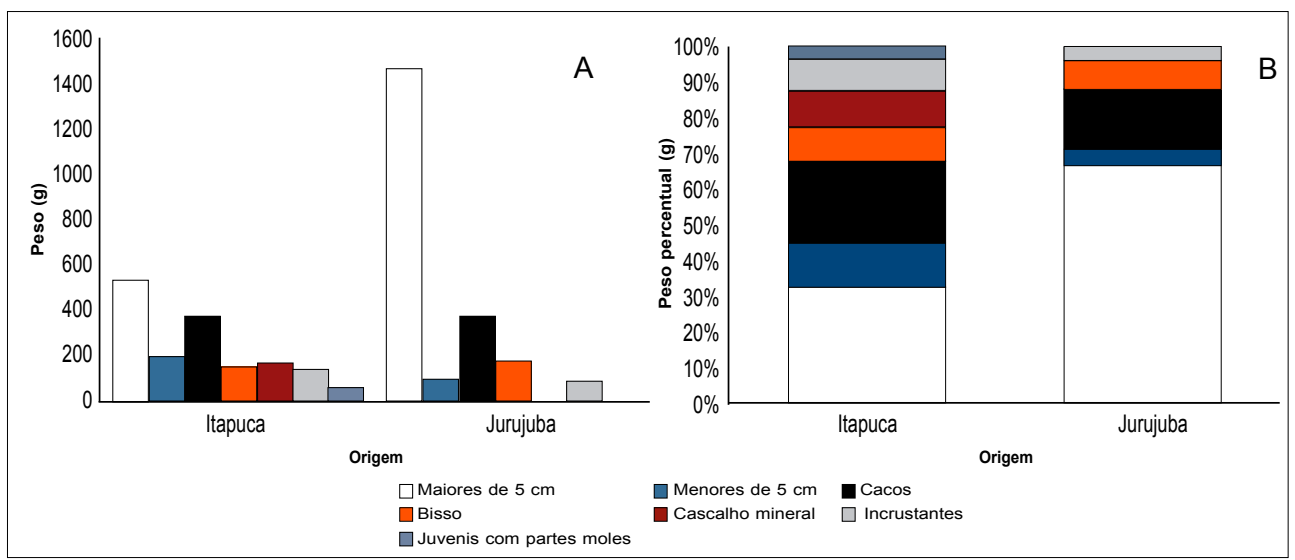

Figura 3 - Diagrama de dispersão, reta de regressão e coeficiente de correlação para comprimento (mm) $\mathrm{x}$ altura $(\mathrm{mm})$ das conchas oriundas da mitilicultura de Jurujuba (esquerda) e da exploração do banco natural da Itapuca (direita)

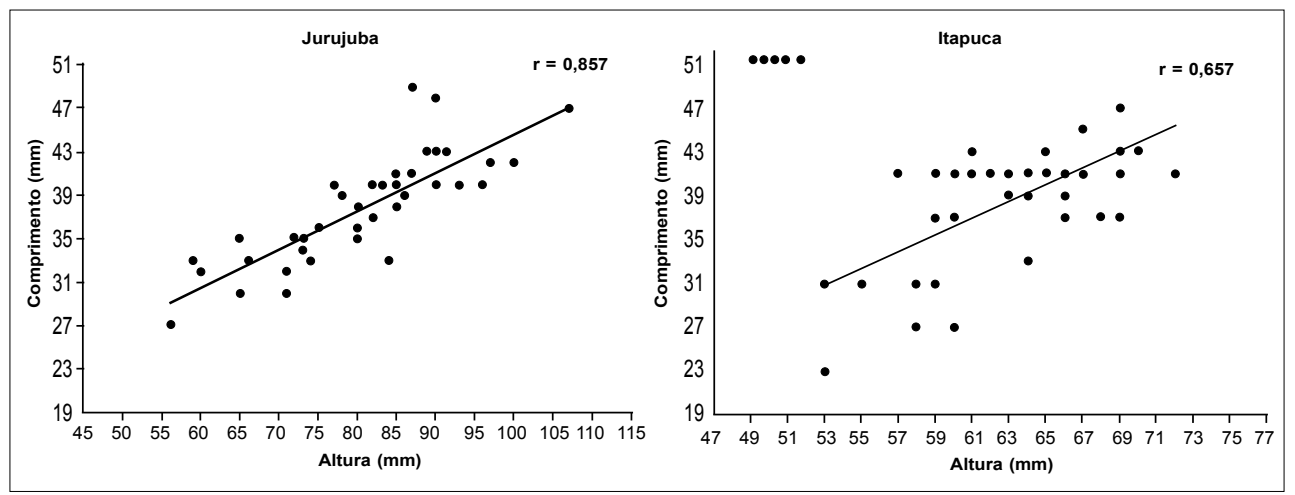

Se for considerada a maior frequência de conchas maiores de $70 \mathrm{~mm}$ como um quesito desejável, pode-se observar mais uma vez que a amostra de Jurujuba seja mais apropriada, visto que a análise da distribuição de frequências demonstra duas modas com valor igual a 8 indivíduos nas classes de 80 e $85 \mathrm{~mm}$ e de 85 a $90 \mathrm{~mm}$ nessa amostra. Enquanto para a amostra da Itapuca a classe de maior frequência (15 indivíduos) seja de 60 a 65 mm (Figura 4).

Entendendo-se as maiores razões entre altura e comprimento como um indicador da assimetria da concha, uma vez que os valores mais elevados correspondem às conchas mais longas e, invariavelmente, menos planas, percebe-se que a amostra da Itapuca é composta por conchas mais assimétricas, embora não apresente diferença significativa da procedente de Jurujuba (Teste $\mathrm{t}$ independente; $\mathrm{t}=1,726 ; \mathrm{GL}=78 ; p=8,8 \%$ ) (Figura 5).

Considerando a menor quantidade de resíduos, maior tamanho, maior área útil e nácar de melhor qualidade, foram utilizadas conchas procedentes dos cultivos em Jurujuba para a confecção de protótipos de objetos de design com alunos de um curso de graduação em Design de Moda, no âmbito de atividades de experimentação desse material. A seguir 
são apresentados aspectos das conchas e do seu local de descarte pelos mitilicultores em Jurujuba, Niterói (Figura 6), e do desenvolvimento dos objetos de design acima mencionados (Figura 7).

Figura 4 - Distribuição de frequências para a altura $(\mathrm{mm})$ das conchas oriundas da exploração do banco natural da Itapuca e da mitilicultura de Jurujuba

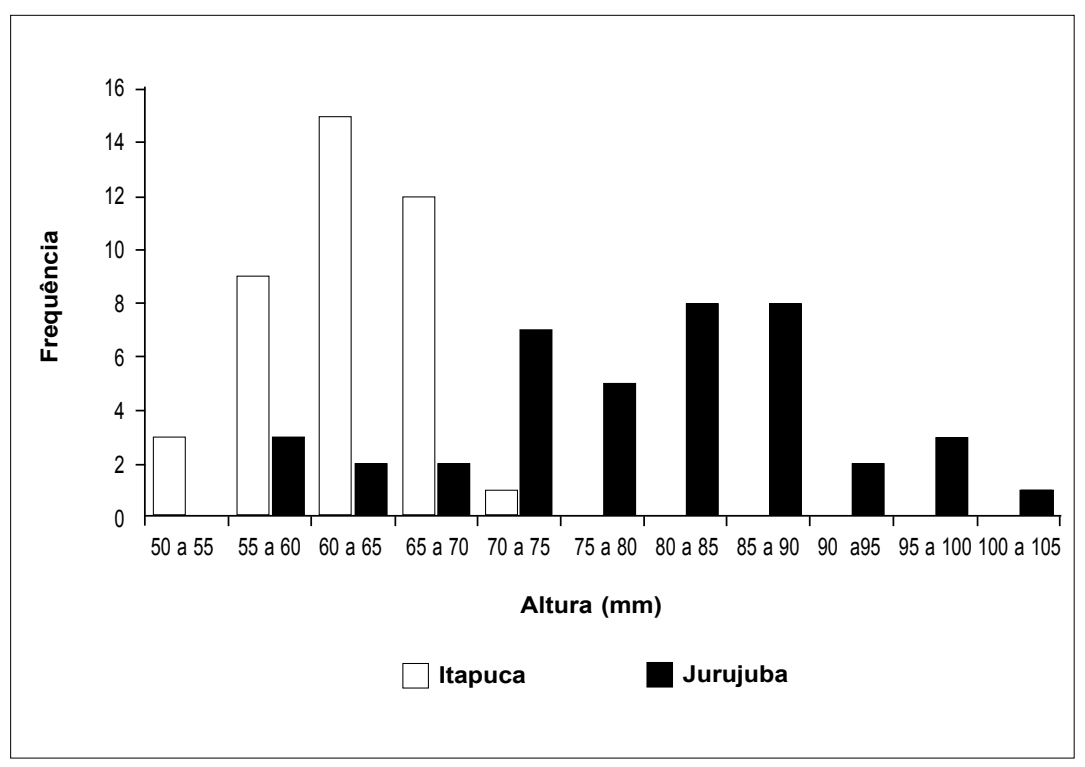

Figura 5 - Valores médios e desvios padrões da razão da altura pelo comprimento (mm) das conchas oriundas da exploração do banco natural da Itapuca e da mitilicultura de Jurujuba

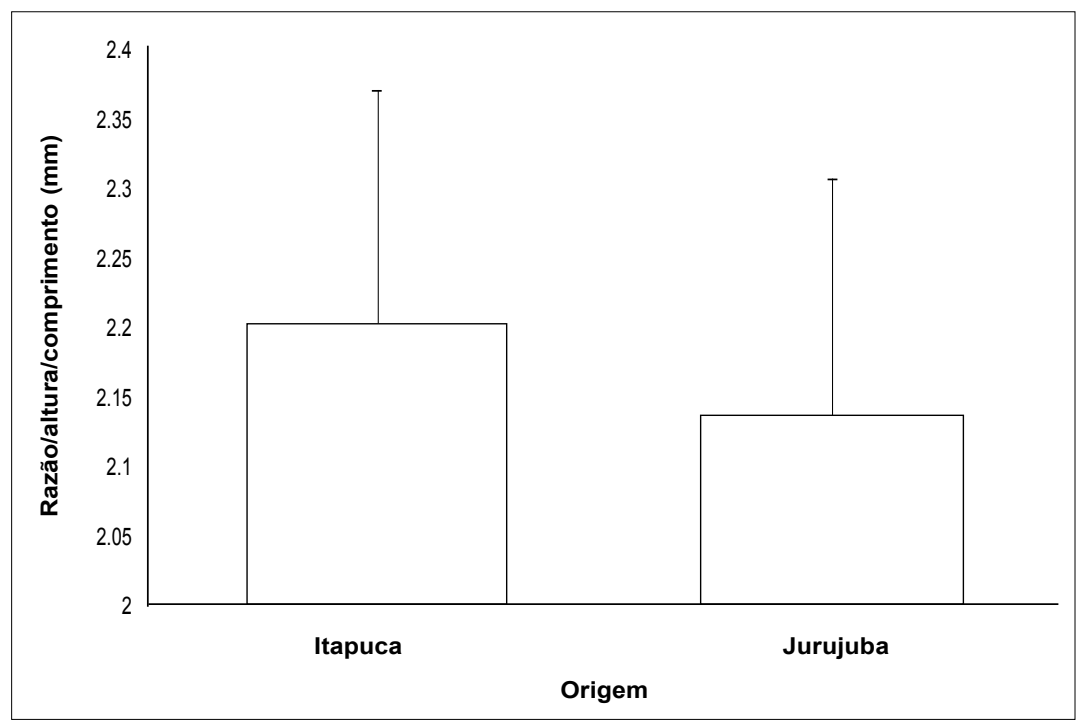


Figura 6 - Aspectos do local de descarte de conchas da mitilicultura em Jurujuba, em Niterói, Rio de Janeiro. A - vista dos cultivos, B, C e D - material descartado, E - instalações rudimentares para o processamento e $\mathrm{F}$ - etapa inicial do processamento
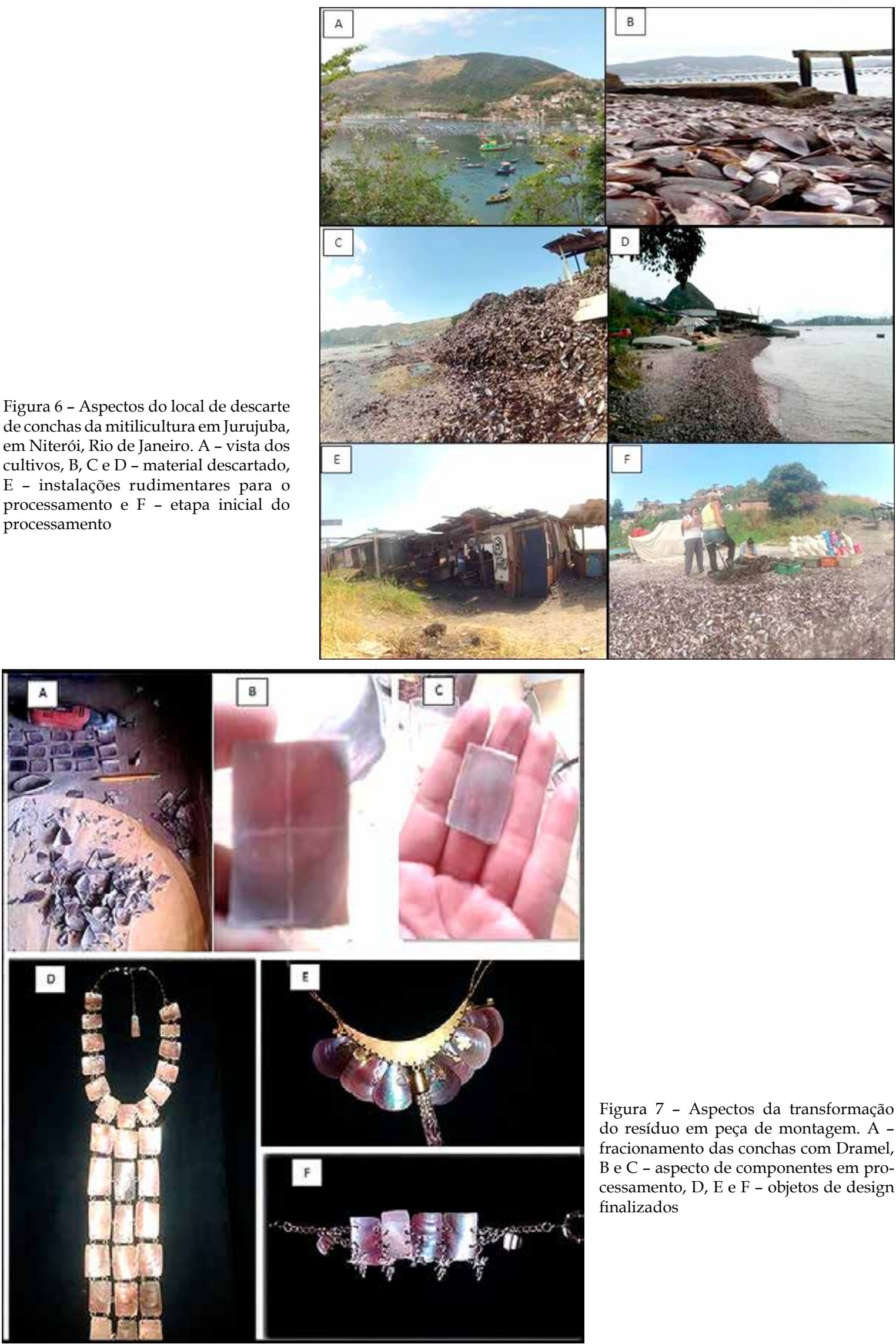

Figura 7 - Aspectos da transformação do resíduo em peça de montagem. A fracionamento das conchas com Dramel, B e C - aspecto de componentes em processamento, D, E e F - objetos de design finalizados 


\section{CONSIDERAÇÕES FINAIS}

Foi evidenciada a inexistência de iniciativas com propósitos semelhantes ao do presente trabalho, uma vez que os estudos existentes se referem a propósitos como: aproveitamento de conchas na construção civil, produção de suplementos alimentares para rações e na correção de solos, como registram Sant ${ }^{\prime}$ Anna et al. (2007), Petrielli (2008), Chierighni et al. (2011), Boicko et al. (2004) e Kwon et al. (2003), entre outros.

Algumas iniciativas já foram desenvolvidas com o propósito de avaliar a simetria das valvas de moluscos bivalves para explicar as influências de parâmetros ambientais na morfologia externa da concha, sem a preocupação com o aproveitamento das conchas, como exemplificado em Lajus et al. (2015) e Briones e Guiñez (2005).

Com relação aos resultados aqui apresentados e tendo-se em vista o uso das conchas no design e artesanato, observou-se a superioridade das conchas provindas de cultivos, no que tange à menor presença de resíduos, à simetria, traduzida pela maior correlação e menor razão entre comprimento e altura, além do maior tamanho das conchas. Destaca-se ainda que o seu uso não implica diretamente em pressões extrativistas sobre os bancos naturais.

A simetria e o maior tamanho são atributos que conferem às conchas de cultivo uma maior área aproveitável e menor concavidade, além do que essas conchas também apresentaram nácar de qualidade estética superior, embora esse último quesito não tenha sido aqui avaliado por métodos objetivos.

A utilização da concha oriunda da mitilicultura como matéria-prima para a confecção de objetos de design e de artesanato pode ser entendida como uma alternativa mitigatória válida, por tratar-se de um resíduo sólido classe II A, como estabelecido na ABNT (1987), que, se encaminhado a um sistema produtivo, reduziria bastante o impacto causado pelo seu acúmulo em pontos da zona costeira brasileira onde ocorre o seu cultivo, incluindo a enseada de Jurujuba.

\section{REFERÊNCIAS BIBLIOGRÁFICAS}

Associação Brasileira de Normas Técnicas. ABNT NBR 10.004. Resíduos sólidos: classificação. ABNT, Rio de Janeiro, 1987.

Boicko, A.L.; Hotza, D. \& Sant'Anna, F.S.P. Utilização de conchas da ostra Crassostrea gigas como carga para produtos de policloreto de vinila (PVC), in Anais IV Simpósio Internacional de Qualidade Ambiental, Porto Alegre, 2004.

Briones, C. \& Guiñez, R. Asimetría bilateral de la forma de las valvas y posición espacial em matrices del chorito Perumytilus purpuratus (Lamarck, 1819) (Bivalvia: Mytilidae). Revista Chilena de História Natural, 78, p. 3-14, 2005.

Chierighini, D.; Bridi, R.; Rocha, A.A. \& Lapa, K.R. Possibilidades do uso das conchas de moluscos, in International Workshop Advances in Cleaner Production, 3, São Paulo, 2011.

Ferreira, J.F \& Magalhães, A.R.M. Cultivo de mexilhões, in Poli, C.R; Poli, A.T.B.; Andreatta, E. \& Beltrame, E. (eds.). Aquicultura: experiências brasileiras. Multitarefa, Florianópolis, 2004.

Freitas, R.R. de \& Barroso, G.F. Conflitos de uso dos recursos costeiros: desafios para sustentabilidade do cultivo de moluscos. Caderno Virtual de Turismo, v. 20, p. 43-50, 2006.

Karlsson, R. \& Luttropp, C. EcoDesign: what's happening? An overview of the subject area of EcoDesign and of the papers in this special issue. Journal of Cleaner Production, v. 14, n. 15-16, p. 1291-1298, 2006. 
Kwon, H.; Lee, C.W.; Jun, B.S.; Yun, J.; Weon, S.Y. \& Koopman, B. Recycling waste oyster shells for eutrophication control. Resources, Conservation and Recycling, Masan, Coreia do Sul, n. 41, p. 75-82, 2003.

Lajus, D.; Katolikova, M.; Strelkov, P. \& Hummel, H. Fluctuating and directional asymmetry of the blue mussel (Mytilus edulis): improving methods of morphological analysis to explore species performance at the northern border of its range. Symmetry, 7, p. 488-514, 2015.

Manzini, E. \& Vezzoli, C. O desenvolvimento de produtos sustentáveis. São Paulo, Universidade de São Paulo, 2011.

Ostrensky, A.; Borghetti, J.R. \& Soto, D. (eds.). Estudo setorial para consolidação de uma aquicultura sustentável no Brasil. Curitiba, 279 p., 2007.

Petrielli, F.A. da S. Viabilidade técnica e econômica da utilização comercial das conchas de ostras descartadas na localidade do Ribeirão da Ilha, Florianópolis, SC. Dissertação de mestrado, Programa de Pós-Graduação em Engenharia Ambiental, Universidade Federal de Santa Catarina, Florianópolis, 2008.

Resgalla Jr., C.; Conceição, M.B. da \& Weber, L.I. O mexilhão Perna perna (L.): biologia, ecologia e aplicações. Interciência, Rio de Janeiro, p. 26-30, 2008.

Ritter, P. “Da favela a Alphaville”: memórias de migrantes alagoanos em Jurujuba, Niterói (RJ), in História oral, v. 16, n. 1, p.189-207, 2013.

Ryan, C. Learning from a Decade (or So) of Eco-Design Experience, Part I. Journal of Industrial Ecology, v. 7, p. 10-2, 2004.

Sant'Anna, F.S.P.A.; Santos, C. de L.; Cesaro, F.; Lemos, S.S.; Berto, R.S. \& Araujo, E.M. Projeto valorização dos resíduos da maricultura. Subprojeto 3: soluções tecnológicas para o aproveitamento de conchas de ostras. Lab. de Gestão Amb. na Indústria. Departamento de Engenharia Sanitária e Ambiental, Universidade Federal de Santa Catarina, Florianópolis, 2007.

Thomas, I. The shell: a world of decoration and ornament. Thames \& Hudson, Londres, 2007. 